\title{
The Impact of Organizational Culture and Performance Work System on Employees' Performance
}

\author{
Amirreza Salehipour ${ }^{1}$, Abdollah Ah mand ${ }^{2}$ \\ ${ }^{1}$ Department of Project Management, Postgraduate Studies Centre, Limkokwing University of Creative \\ Technology, Malaysia \\ ${ }^{2}$ Department of Economics, Faculty of Economics and Management, University Kebangsaan Malaysia, Malaysia \\ Correspondence: Amirreza Salehipour, Department of Project Management, Postgraduate Studies Centre, \\ Limkokwing University of Creative Technology, Malaysia.
}

Received: April 21, 2018

doi:10.5539/ibr.v11n6p199

\author{
Accepted: May 16, 2018 \\ Online Published: May 25, 2018 \\ URL: https://doi.org/10.5539/ibr.v11n6p199
}

\begin{abstract}
Necessity of improving employees' performance in ministry of education in Iran was the reason of conducting this research. Authors are focused on the impact of High Performance Work System (HPWS) and the culture of organization on employees' performance in Iran ministry of education. By conducting specified study based on distributed survey questionnaire to 162 members of ministry of education in Iran, this study aims to provide answer to the given research questions of study. The outcome of hypotheses testing illustrate HPWS significantly effects ministry members' performance and shows strong relation between variables. Likewise, organizational culture demonstrates significant affirmative impact on Iran ministry of education members and employees' performance. Findings of current research indicate that the ministry of education in Iran requires immediate action toward improving performance of members to obtain desired outcome. Accordingly, to the result of present study, current research attempts to provide practical concepts and illustrate limitations, suggestions for improvement of ministry and future study in this field.
\end{abstract}

Keywords: High Performance Work System HPWS, Performance Management System PMS, selective training and development, individual roles and employee performance

\section{Introduction}

Competitiveness among the private and public organizations with customers and shareholders' demand demonstrate desire economic continuing improvement and change. According to Tsui et al (2013) in order to tolerate this competitive environment organization required to highly improve and develop performance of employees. Refer to the mentioned issue, employees need to involve and improve their operations to achieve organizations' objectives. This is because staffs 'perform is believed to operate significant role in influencing organizational achievement of required initiatives, which described by Sparrowe et al.(2001) as a key factor that lead the organization into desired performance.

This study is motivated from the importance of employee's performance on fulfilling the objectives of organizations and lacking of such research for organizational culture and performance work system in Iran. Generally, organizations' objectives such as service quality, customer satisfaction and loyalty, etc. are depend on employee's performance Tsui et al. (2013).Thus, firm's' objectives are likely achievable by paying attention to individual performance synchronization toward organizations' goals.

Anitha (2014) defined performance of employees as the financial or non-financial consequence of the employee that directly connected with both the operation of the firm and its success. In a changing work environment, members of organizations may have various tendency and behavioural action, which will result to noticeable inconsistency in their performance Chen and Wang (2014). This is due to the accepted expectation that performance of an individual will highly relay on the strategy and execution that has been embraced by an organisation Anitha (2014).

However, some support improvement performance indicators directly related to knowledge gains Wu et al. 2013. The transfer, creation and use of knowledge require the existence of an organizational culture in which individuals and groups tend to cooperate with each other and share their knowledge in a manner that is mutually 
beneficial Kuchaki and Siahkhale (2012). As a result, a major priority was giving to developing the skills of the country labour force in order to meet the country needs Ministry of Information (2008). Furthermore, performance management system is another problem hindering employee's performance in the ministry. For instance, Hilal (2012) argued that teachers cannot be efficiently productive, unless the evaluation is accomplished attentively with significant consideration to all evaluation process aspects.

Thus, employee's influence with respect to culture of employees on the performance of companies is crucial issue and there is urgent need to investigate about it. Additionally, evidences on Iran are very rare on the culture of employee's and performances of companies.

\section{Theory Literature}

\subsection{Employee Performance}

\subsubsection{Defining Employee Performance}

Business researchers and management scholars are mainly concerned in identifying the most significant definition of employee's performance. Even though employee's performance has become a common phenomenon in management studies and makes its definition and structure reliable and explicitly justified March and Sutton (1997). Additionally, as mentioned earlier, Anitha (2014) defined employee performance as the financial or non-financial outcome of the employee that has a direct link with both the performance of the organisation and its success.

\subsection{Dimensions of Employee Performance}

Organizational researchers have made performance a definitive dependent variable of importance Richard et al. (2009). In a nutshell, the most significant criterion to examine employee's performance, organizations, their environments, and actions is through organizational performance Richard et al. (2009). Due to inability to identify dimensional of employee's performance, researchers have resulted to multi-dimensional system of performance measurement.

\subsection{Issues on High Performance Working System}

Over the past decades, academic scholars and practitioners have argued on the ways in which human resource practices of an organization are used in such a way that the employer attain the maximum achievable advantage from their abilities and the employees equally achieve material and psychological benefit from exerting their energy Graham (1978). This argument has led to the formulation of wide range of theories or models that link human resource management strategy with the general organizational strategy Schuler and Jackson (1987).

\subsubsection{Defining High Performance Working System}

Scholars and practitioners explored that both employees and organizational operation can be significantly enhancing by its human resource practices that influence human capital by acquiring, developing and encouraging the best talent Posthuma et al. (2013). The system was originated back to the American tradition of human resource management, based on the argument that involvement of employee is significant to organizational performance Ferreira et al. (2012). They also defined HPWS as systems of managerial practices that facilitate the increasing employee empowerment and increase the incentives and skills that will motivate and enable them to benefit from this better empowerment.

\subsubsection{Dimensions of High Performance Working System}

There is no generally acceptable element in measuring HPWS. Rather, researchers have used different dimensions suitable to their context Edwards et al. (2006). In order to understand HPWS, it is imperative to know how HPWS have been measured previously by various researchers in order to understand why the researcher chooses to measure HPWS in multidimensional approach.

\subsubsection{Performance Management System}

At the heart of organizational management, effort have been made to change some of the difficulty facing organization, one fundamental reform approach is to promote performance management (OECD, 2005). According to Moynihan (2008), performance management is a system that link performance information to organizational decision making. In a study, Ferreira and Otley (2009) defined performance management system as defining, controlling and managing both the attainment of outcome or ends and the means in achieving the result at a societal and organizational level rather than individual level. It has also been argued that PMS involve steps that include strategic planning, setting goals, progress measurement in the form of objectives, and using 
performance feedback to improve operational efficiency of the system, enhance policy making, encourage better resource allocation and increase accountability (Moynihan, 2008).

Ezati Mitra (2017) categorizes the barriers in employees' performance within the ministry into two categories external and internal. The external constraints include, lack of training and information, lack of authority, financial challenges, as well as the relationship between school and General Directorate (General Directorate Intervention), while the internal challenges include, lack of information and collaboration, lack of teacher's participation in decision making process, stress initiated from overload work, and lack of budget or unfixed amount of financial support (Ezati M. 2017).Researchers also identified lack of implementation of high performance work system as one of the most important problems facing employee's performance in the ministry (Ezati M. 2017).

\subsubsection{Selective Training and Improvement}

Training is one of significant and unfailing human resource method to improve employees 'efficiency (Bhatti \& Kaur, 2009). In an effort to achieve organizational task and enhance employee performance, training and development program ought to be selectively schemed in a way that create a win-win situation for both employee and the organization in general (Bhatti, \& Kaur, 2010). Selective training develops employee's knowledge and personality, as a result compatibility to working environment increase and their performance accordingly improves. Therefore, recognizing the accurate employees to be trained would shrink down organizational cost of training and development (Vlachos, 2011). This demonstrated that training and development are keys to organizational success and help sustain competitive advantage and employee retention (Ahmad \& Schroeder 2003; Atteya, 2012). It provides employees with the needed knowledge, skills to effectively perform the required task and permit the organization to update modern work practices (Atteya, 2012).

\subsubsection{Individual Role}

Progressively, organizations are in search for members who not just believes working in nice and flexible environment but looking for people who committed to their organization and believe that their destiny depends on the organization's destiny (Epitropaki \& Martin, 2005). Therefore, individual's operation on overall employees 'performance of the organizational has been to a great extent under-researcher, (Mollick, 2012), even though conceptual work had recommended that individual role can possible link to the achievement of better performance (e.g de Waal, 2007). Particularly, in an established organization where economic of scale and scope are significant such as the Iran Ministry of Education there certainly appears to be little need to take into account the role of individual in enhancing the overall performance of employees in the organization (Mollick, 2012).

\subsection{Organizational Culture}

\subsubsection{Defining Organizational Culture}

The term culture originated from a Latin world colure or culture meaning cultivating, growing as well as caring (Yuksel, 2006). There have been numerous views about organizational culture this has resulted to different definitions. For instance, Scott, Mannion, Davies and Marshall (2003), defined organizational culture as a wide range of social phenomena that help to define an organization's character in addition to norms, customary dress, language, behaviour, beliefs, value, assumption, symbols of status with authority, myths, ceremony along with rituals, and form of respect and subversion. Again, Eroglu (2007), defined culture as the overall information, belief, art, ethics, law, custom, habit and the skills brought by individual to the society in which they belong. Similarly, Aksoy et al. (2014), described organizational culture as the value of an institution, created not only by the manners and behaviours of every single person in the organization, but the joint attitudes and behaviour of the organization in general. A study by Armstrong (2006), defined organizational culture as the pattern of values, norms, beliefs, attitudes as well as assumptions that may not have been expressed but shaped the ways in which people in an organization conduct themselves and get things done.

\subsubsection{Dimension of Organizational Culture}

A major argument among cultural theorists has been the question of whether should be studied in homogeneous or heterogeneous approach (Alavi et al. 2006). For instance, Cameron and Rohrbaugh (1983), developed the famous competing value framework $(\mathrm{CVF})$ that categorize organizational culture into four types such as clan, adhocracy, market, and hierarchy. Thereafter, Cameron and Quinn (2011),explained these four dimensions of culture as: A clan culture is a family type of culture that works closely together with commitment and loyalty to each other; adhocracy culture is self-motivated, innovative and entrepreneurial, placing value on creative innovation in addition to allowing employees to take risks; While market culture place emphasis on output in 
addition to results oriented and competition for customers, contractors, and regulators; Finally they defined hierarchy culture as unwavering controlled by rules, guiding principle, scheduling, in addition to lowering costs. Furthermore, in a most recent study by Ovidiu Iliuta(2014), put organizational cultural dimension into adaptability, mission consistency and involvement. The researcher therefore argued that notwithstanding the organizational cultural dimensions, an organization should align its core value with its overall performance. That a negative and non-transparent culture leads to high rate of agitation (Ovidiu Iliuta 2014). This is why it better for an organization to only focus on the type of culture that will create better employee's performance and that will help employees who do not achieve their objective before looking for a better match for the employee position (Ovidiu Iliuta 2014).

\subsection{Relation between HPWS and Employees performance}

Wright and Nishii (2012) argued that employee attitudes and behaviours will be influenced by perceived HR practices. Similarly, it is only the perceived HPWS which configures employees' attitude and the behaviour and making them to put in their best (Guest 1999). Using a sample of 700 of organization's member in China Zhang, Di Fan and Zhu (2014) found that HPWS which satisfies employees and provides effective loyalty and greater voluntary efforts toward performance improvement.

Scholars conceptualize HPWPs as a set of distinct but interrelated HR practices that incorporate, select, develop, retain, and motivate a workforce (Huselid, 2017).

\subsection{Relation between Organization Culture and Employee Performance}

The linkage among organizational culture and performance has received great deal of attention from scholars in the field of organizational culture (Ogbonna and Harris, 2000; Henri, 2006). Stoica et al. (2004) asserted that the relationship between culture and performance is influenced by the way organizations search for and use information. Therefore, comprehending the correlation between organizational culture and employee's task performance is an important research subject because detections of various studies have demonstrated that an individual's work performance is vital element toward the success of organizations (Shahzad et al.2013).

\subsection{The Possible under Pinning Theory}

This study predicted that resource base view (RBV) and contingency theory will be use for the purpose of this study.

\subsubsection{Resource Base View Theory}

The resource base view of a firm provides the understanding underlying performance among organization: the possession of inimitable organizational practices direct organizations to outperforming others as a result illustrates the major source of stable competitiveness advantage (Alegre et al. 2011). Hence, the HPWS of an organization performs as a competitive advantage for the organization as functions of complex inimitable resources well-established within the organization (Alegre et al. 2011).

According to Peng and York (2001), the RBV help to determining performance at organizational level and it's extensively regarded as a major advantage for an organization, and provide a platform that link HPWS and organizational culture with employee's performance. HPWS and unique culture of the organization will serve as rare resources if organization is able to employ it in a unique way (Peng and York 2001). Drawing on this, it has generally been theorized that high performance work system stimulate high performance by increasing the degree of human and social capital within the firm (Lepak et al. 2007) and at the same time motivate employee behaviours that creatively use organizational resource toward organizations' scheme (Appelbaum et al. 2000).

\section{Research Method}

This study is intended to examine the high performance work system impact and organizational culture on performance of employees in the Iran Ministry of Education. In order to achieve this objective, key element such as research framework, research design and method that have been used in this research will be discuss.

\subsection{Research Framework}

The research framework presented below comprises of three key variables. They include high performance work system (HPWS), organizational culture and employee's performance. HPWS which is the major element that the present study is aimed to examine in public organization has three dimensions. These variables will be investigated in an effort to establish their impact on public organizations. The study adopted a research framework recommended by Messersmith and Guthrie (2010), which investigate HPWS among a sample of young high technology firms in United States. This study expands their framework by including the role of individual to the framework. In the same way by examine this framework different context and sector such as 
Iranian Ministry of Education.

\subsection{Research Hypothesis}

This study aims to examining the relation between HPWS, organizational culture and the performance of employees in Iran Ministry of Education. Therefore, the followings are the research proposed hypotheses to be tested.

H1: High performance work system has a positive relation with employees' performance.

H1a: Performance management system has positive relation with employees' performance.

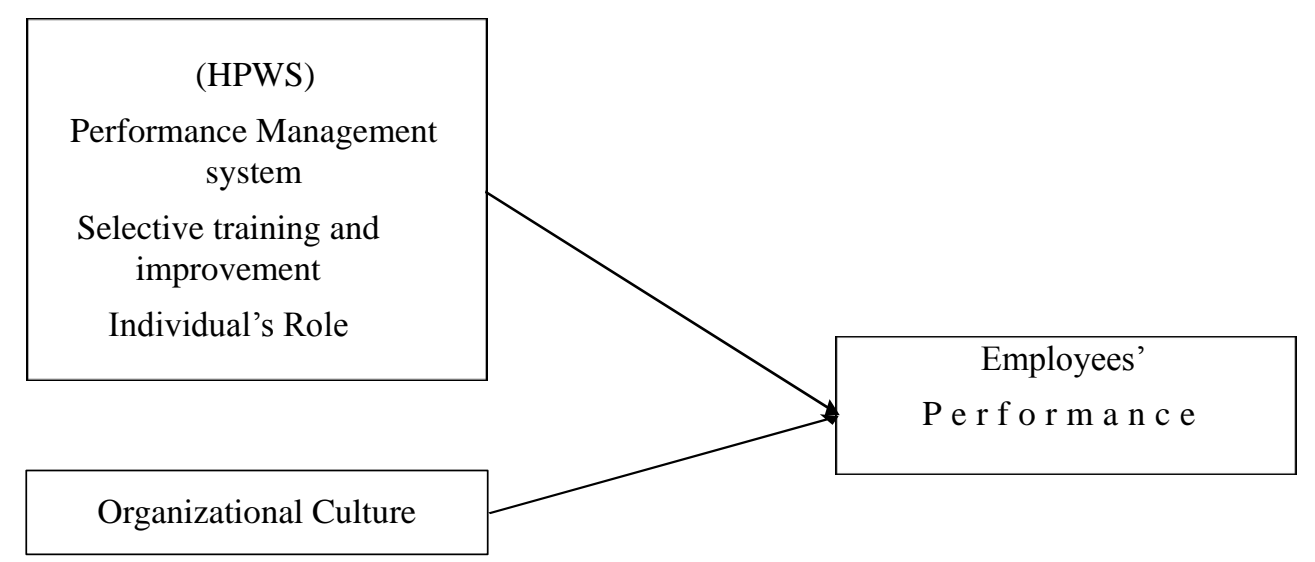

H1b: Selective training and improvement has affirmative relation with employees' performance.

H1c: Individual role has affirmative correlation with overall employees' performance of Iran ministry of education.

H2: Organizational culture has affirmative relation with employees' performance.

\subsection{Research Design}

The researcher classifies research approach into two, such as: quantitative and qualitative research (Neil 2009). In this study, the researcher adopted a quantitative approach in an effort to test the relationship between the research variables (Kreuger and Neuman 2006).

\subsection{Population and Sampling Design}

\subsubsection{Population}

Population refers to group of people that share common characteristic (Zikmund 2003). Based on the available statistic provided by the Directorate General of Human Resource Development in the Iranian Ministry of Education, there are more than one million employees in the Iranian Ministry of Education (Ministry of Education 2017).

Considering that, it is not practically realistic to conduct a survey on all the employees in the Ministry of Education (Zikmund 2003), two hundred and eighty-two (282) employees in the Directorate General of Human Resource Development form the population for this study. This is due to the employees in this directorate evaluate development and provide training for all other directorates, yet employees within the HR directorate lack performance management system. This has also weakened the performance of employees within this ministry as majority of the employees have no feedback about their performance. The list was obtained from the Directorate General of Human Resource Development which serves as best source regarding employment information. The list combines all the employees in the Ministry of Education including the teachers.

\subsubsection{Sampling Size}

A sample is the subset of a population (Zikmund 2003). Considering it is not completely reasonable to obtain all the data from this population, for this reason it is very important to decide the sample size (Zikmund 2003). Determining sample size Roscoe (1975), recommended a sample between 30 and less than 500. In the same view, Krejcie and Morgan (1970) a sample size of 162 to be a good sample. Therefore, to avoid problem of response bias and to increase the response rate for this study, the researcher decides to use a sample of 200 as a sample size for this study. 


\subsubsection{Sampling Techniques}

In this study, a simple random sampling technique was utilizing to select 200 employees from the Directorate General of Human Resource Development. This is because it provides researchers the freedom to include all elements in the population (Zidmud 2003). The list and the names of the employees were obtained from the secretary of the head of the director's office. This list contains the number of employees in each department and their job title. Thereafter, researchers put all the names into a basket and continuously starring the basket in the process selecting every element out of the large population until the researcher achieve the required number of sample size that was suitable for this study.

\subsection{Instrument of Study}

\subsubsection{Employees Performance}

In this study, employee's performance is the outcome variable that HPWS practices and organizational culture will influence. Hence organizational performance is operating as the action or behaviours that are significant to organizational goal and that can be measured in terms of every individual level of contribution (Mohrman et al.1989). In this study employee's performance was measured by eight items developed by (Jelinek et al. 2006). Previously, studies have reported that these items have satisfactory internal consistencies with a Cronbach alpha of 0.7 and above (Goldston 2007; Mansor et al. 2012).

\subsubsection{High Performance Work System}

A high performance work system is operating in this study as a set of distinct but interrelated HR practices that, taken together, select, develop, retain, and motivate a workforce (Becker and Huselid 1998; Guthrie 2001). High performance work system was measure with three dimensions, all items in these dimension were adopted from previous studies and were found to have a high validity and reliability.

\subsubsection{Performance Management System}

Performance management is operating in this study a process of delivering strengthened success to organizations by improving capabilities of individual and team (Mansor et al. 2012). In this study performance management was measure with six items adopted from a study by Mansor et al. (2012).

\subsubsection{Selective Training and Development}

Selective training and improvement refers to organized improvement and skills acquisition, also required attitudes and knowledge by employee's to effectively improve their operation in the organization environment (Goldstein 1993). In this study, ten items were used to measure selective training and development and they were adopted and modified from a study by Ahmad and Schroeder (2003); Jensen et al. (2013); Vlachos (2011).

\subsubsection{Individual Duty}

Organizations' function significantly impacts by individual performance. Employees must be persuaded, compel or obligated to take part in the organizational operation. Strong attraction identified amongst employees' motivation and their organizational identification. Organization member's identification level is subject to character and passion or their reason of taking part in that firm. The member's relation with organization will improve if their individual's requirements pleased in it. In this study the role of individual is measured with seven items adopted from (Goldston 2007).

\subsubsection{Organizational Culture}

Organizational culture is operating in this study as a common view of workplace practices within an organizational unit that differentiate it from other organization (Van den Berg and Wilderom 2004). As shown in Table 3.1 organizational culture was measured by ten (10) items developed by (Van den Berg and Wilderom 2004). These items have been used by other researchers and they show to be valid and reliable for measuring organizational culture (Aksoyet al. 2014; Wilderom et al. 2012). All items in this study are subject to seven point likert scale from strongly disagreeing to strongly agree. Table 3.2 shown items on organizational culture. 
Table 3.1. Organizational culture Scale

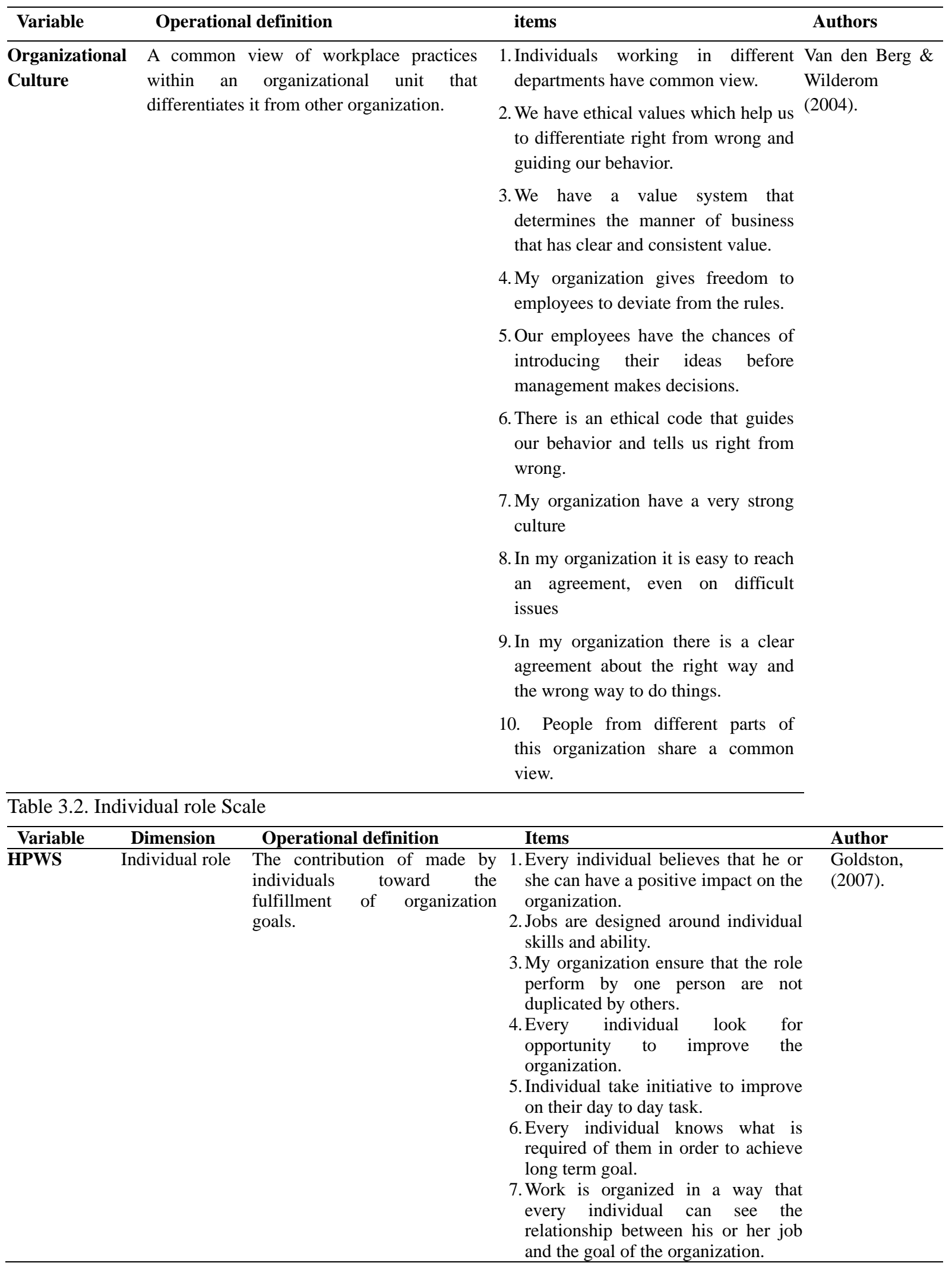

\subsection{Layout of Questionnaire}

The questionnaires in this study was first developed in English, but latter translated to Farsi because all the employees in the Iran Ministry of Education medium of communication is Persian, hence translating the questionnaire to Persian will give the respondents more understanding in answering the questionnaire. The 
translation was done by one of the directors in charge of training.

The questionnaire covers 6 pages close ended question to obtain information about HPWS dimensions such as performance management, individual role, and selective training and development.

\subsection{Pilot Test}

It is very important for a researcher to conduct a pilot study so as to know the internal reliability (Litwin 1995), in order to provide a solid foundation for the main study. Consistent with this claim, the Cronbach coefficient alpha was conducted in order to measure the internal consistency reliability of the items used in this study.

\subsection{Technique of Data Analysis}

The normality and outliers was first conducted prior reliability analysis. Statistical Package for the Social Science (SPSS) used to analysing the data version 20. Five following techniques were employed in the process of analysing the data for the main study using SPSS; cleaning and screening of data, descriptive statistics, factor and reliability analysis, Pearson correlation analysis, multiple regression analysis.

\section{Result and Discussion}

\subsection{Response Rate}

To conduct the study data collected from employees in the rank of managers, directors and other employees in the Human Resource Management Development of the Ministry of Education in Iran. In an effort to increase the response rate, telephone calls and send message short (SMS) were put across to those employees who the enumerator or the secretary could not be able to collected their response. Due to this attempt 162 questionnaire were retrieved out of 200 survey distributed. This makes a response rate of 81 percent (\%). Giving the recommendation by Hair et al. (2010) a response rate of $30 \%$ and above is satisfactory for a survey. Table 4.1 below indicate the total number of survey distributed, collected from the employees and the number of questionnaire that had been completely filled by the respondents.

Table 4.1. The total number of survey distributed

\begin{tabular}{lll}
\hline & Number & \% \\
\hline Distribute & 200 & $100 \%$ \\
Responded & 162 & $81 \%$ \\
Completed & 156 & $78 \%$ \\
\hline
\end{tabular}

From the above table, this study recorded a response rate of $81 \%$. Therefore, a response rate of 81 percent $(\%)$ recorded in this study is believed to be a great achievement. Again out of the 162 questionnaire that returned 6 questionnaires i.e. (3\%) could not be processed as they were partially filled, consequently they were removed (Bell and Bryman 2007).

\subsection{Descriptive Analysis}

Literature has argued that descriptive analysis is conducted following data screening and cleaning. Accordingly, Pallant (2007) avowed that descriptive analysis helps to explain the characteristics of the respondents who have involved in a study. It explains the characteristics of the sample in addition to addressing some specific research issues. The information is presented in Table 4.2. 
Table 4.2. Demographic

\begin{tabular}{|c|c|c|c|}
\hline Category & Items & No. Of Respondents & Percentage \\
\hline \multirow[t]{2}{*}{ Gender } & Male & 65 & 40.1 \\
\hline & Female & 97 & 59.9 \\
\hline \multirow[t]{5}{*}{ Age } & $18-20$ & 1 & 0.60 \\
\hline & $21-30$ & 12 & 7.40 \\
\hline & $31-40$ & 75 & 46.30 \\
\hline & $41-50$ & 63 & 38.90 \\
\hline & More than 51 years old & 11 & 6.80 \\
\hline \multirow{4}{*}{ Designation } & Director & 2 & 1.20 \\
\hline & Deputy Director & 6 & 3.90 \\
\hline & Head Section & 16 & 9.90 \\
\hline & Others & 138 & 85.2 \\
\hline \multirow[t]{4}{*}{ Educational Qualification } & Doctorate Degree & 17 & \\
\hline & Master Degree & 73 & \\
\hline & Bachelor & 57 & \\
\hline & Diploma & 15 & \\
\hline \multirow[t]{4}{*}{ Work Experience } & Less than one year & 3 & 1.90 \\
\hline & $1-5$ years & 7 & 4.30 \\
\hline & $6-10$ years & 17 & 10.50 \\
\hline & More than 11 years & 135 & 83.30 \\
\hline \multirow[t]{6}{*}{ Department } & Director Office & 27 & 16.70 \\
\hline & $\begin{array}{c}\text { School performance } \\
\text { Development }\end{array}$ & 31 & 19.10 \\
\hline & Educational Supervision & 23 & 14.20 \\
\hline & Main training Centre & 43 & 26.50 \\
\hline & Training and Upgrading & 22 & 13.60 \\
\hline & Evaluation of Training & 16 & 9.90 \\
\hline Total & & 162 & 100 \\
\hline
\end{tabular}

The above table is the demographic profile of respondents that participated in this survey from Directorate of Human Resource Development in the Iran Ministry of Education. With deep respect to the sex of the respondent it is evident from the above (Table 4.2) that majority of the respondents in the ministry are female (59.9\%), followed by $40.1 \%$ responders which are male. These results support the notion that female employees constitute majority in nearly everyone public institutions. The response represents employees that were categorize into five different age grade 18-20 (0.6\%), 21-30 (7.4\%), 31-40 (46.3\%), 41-50 (38.9\%) and 51-61(6.8\%). Although there exist contract employees in Iran education ministry which are not considered as member of the organization. If no prediction is made for replacement, it is likely going to be a great vacancy in this organization while the big number of employees in the ministry seems to be retired soon.

As for the designation of those that participate in the survey from this ministry. A total number of $2(1.2 \%), 6(3.9)$ directors and deputy directors respectively personally participated in the survey. It is very rare for directors in this ministry to be fully involved in a survey as the researcher had witness in the past survey because of their busy nature. Their desire to be involved in the survey further shows the importance of this study to the ministry. Only $9.9 \%$ on the position of the head section constitute the respondents for this study. Furthermore, $85.2 \%$ of the employees in this study are within the rank of other positions as at the time of collecting data for the study, this informs the researchers that the sample is a true representative.

The table above also shows that majority of respondents in the Ministry of Education holds master degree and above (doctorate degree 10.5\%, master degree $45.1 \%$ ). The reason could be heathen by the current need by people to upgrade their knowledge irrespective of the position held in the organization. Also in this study, bachelor degree form $35.2 \%$ this may be influenced by the assumption that bachelor degree is gradually turning to be the minimum qualification for any organization whether public or private. While only $9.3 \%$ of employees that participated in this survey had diploma as at the period of this study.

In terms of employees work experience in the Ministry of Education in Iran that takes part of this study. The researcher found that $83.3 \%$ have eleven years' experience of working in the ministry. The above result justifies that most employees that participated in the survey tend to be experienced in the ministry hence; they are believed to have expertise and experience about human resource practices in the organization. This followed by 
employees with six to ten years (10.5\%). While employees between 1-5 years' experience constitute 4.3 of this study, only $1.9 \%$ of the employees that have less than one year were engage in this study.

Concerning the department that employees that participate in this survey, Main Training Centre have the majority forming a total of $26.5 \%$. While $19.1 \%$ are from School Performance Development. Another $16.7 \%$ were representative from the director's office. While $14.2 \%, 13.6 \%, 9.9 \%$ are representative from Educational Supervision Department, Training and Upgrading Department and Evaluation Training Impacts Department respectively. The above statistics justify that most all the department in the ministry were fully represented.

\subsection{Reliability Analysis after Factor Analysis}

It is vital for scholar to study and make sure that utilize reliable measurement for the sampling in a research. As a result, Sekaran and Bougie (2010) defined reliability as a measuring instrument that measures the consistency of an instrument. Drawing on this assertion, it is vital for the present study to review the internal consistency of the measurement that utilized. Cronbach's Alpha indicator adopted to evaluate the study as predictor of the internal consistency. According to Pallant (2007) a Cronbach alpha coefficient of 0.50 and above is suitable for a study. Fornell and Larcker (1981) also recommended that a composite reliability of 0.70 and above is acceptable. Hair et al. (2010) assert that a loading above 0.50 is significant.

Table 4.3. Reliability Analysis of performance management system, selective training and improvement, individual duty, organizational culture and employee's performance after factor analysis

\begin{tabular}{lcc}
\hline Variables & Items number & Cronbach's Alpha Scores \\
\hline Employees performance & 6 & 0.821 \\
Performance & 5 & 0.743 \\
management system & & \\
Selective training and & 7 & 0.801 \\
development & & \\
Individual duty & 6 & 0.857 \\
Organizational culture & 8 & 0.872 \\
\hline
\end{tabular}

4.4 Hypotheses Testing

In this study, correlation analysis was conducted through linear regressions. Particularly, the Pearson correlation analysis was adopted in order to examine and offer a more understanding of the strength of the linkage between HPW, organizational culture and employee's performance. In the same way, regression analysis applied to establish the direct relation between the explanatory and response variables.

\subsection{Correlation Analysis Test}

The correlation analysis was done in order to compare and know how related these items are. Literature has argued that the value of correlation is to assist the researcher in establishing issues of multi-collinearity (Mayers et al. 2006). Considering issues of multi-collinearity, Cooper and Schindler (2003) affirmed that no precise standard in establishing the level of correlation between variables that have multi-collinearity cases. They argued that a correlation that is 0.80 and above may be problematic for this reason, a lower correlation is acceptable.

The result of the correlation analysis shows in table 4.4 revealed that performance management system has a value of -0.329 with a significant level of 0.000 . This demonstrated that, there is no founded or negative relation amongst performance management system and employee's performance. Again, the result of the correlation analysis showed that selective training and development has a correlation coefficient of 593 at 0.000 a significant level. This suggests that, there is a significant positive relation between selective training and development and employee's performance. More so, it is evidence in the correlation analysis result in Table 4.4 that the role of individual is correlated with employee's performance at a value of 0.686 with 0.000 significant levels.

This showed that, there is a significant positive relationship between individual role and employee's performance. Finally, the result demonstrated a correlation of 0.684 between organizational culture and employee's performance at 0.000 significant levels. It signifies that there is substantial affirmative correlation amongst organizational culture and employee's performance. Table 4.4 showed the analysis summary of the correlation between HPWS dimensions, organizational culture and employees performance. 
Table 4.4. Correlation result of HPWS dimension to employee's performance

\begin{tabular}{lcc}
\hline Independent variable & $\begin{array}{l}\text { Dependent(Organizational } \\
\text { performance) }\end{array}$ & Significant level \\
\hline Performance management & $-.329^{* *}$ & 000 \\
system & $.593^{* *}$ & .000 \\
Selective training and & & .000 \\
improvement & $.686^{* *}$ & .000 \\
Individual duty & $.684^{* *}$ & \\
Organizational culture &
\end{tabular}

$* * \mathrm{P}<0.05$

In accordance with Cooper and Schindler (2003), this study concluded that there is a relationship between HPWS dimensions, organizational culture and employee's performance. According to Zikmund (2003), correlation does not involve cause and effect no matter how satisfactory significant it is. This provides the basis for further analysis.

\subsection{Regression Analysis}

The multiple regression analysis was carried out in order to determine the variable or dimension that has stronger or weaker relationships to employee's performance. The regression analysis in Table 4.5 shows that $59.1 \%$ ( $R$ square $=0.591$ ) the variance of employee's performance have been significantly explained by HPWS dimensions and organizational culture. This is due to the high value of beta they enclose in explaining employee's performance. Individual role seems to have the highest contribution to the overall performance of employees in the Ministry of Education with beta value of $(\beta=0.370)$, followed by organizational culture $(\beta=0.324)$, selective training and development $(\beta=0.179)$ and performance management system contributing the least value to employee's performance $(\beta=0.028)$. The result is showed in Table 4.5 below.

Table 4.5. Regression Analysis

\begin{tabular}{lcc}
\hline Variables & Beta $(ß)$ & Sig \\
\hline Performance management system & 0.028 & 0.626 \\
Selective training and improvement & 0.179 & $0.000^{* *}$ \\
Individual duty & 0.370 & $0.001^{* *}$ \\
Organizational culture & 0.324 & $0.000^{* *}$ \\
$\mathrm{R}$-squared=.591 F=53.457 & & \\
\hline
\end{tabular}

$* \mathrm{P}<0.10, * *<0.05, * * * \mathrm{p}<0.001$, Sig $=$ Significant, NS = Not Significant

Table 4.5 above demonstrates the multiple regression analysis of HPWS dimensions, organizational culture to employee's performance. In order to confirm the model presented in this study, via testing of the main hypothesis, a multiple regression analysis results were presented at the significant level of $p<0.05$. The first task before the researcher is to confirm the hypotheses as regards to the relation amongst high performance work system dimensions, organizational culture and employee's performance. The next subsection shows the hypothesis decision from the regression result.

Findings of this are similar to the findings of other developing country in the region. Shahzad et al. (2013) in a software houses conducted in Pakistan found that there is a positive relationship between organizational culture and employee's job performance. Consequently, they recommended that it is very useful to increase the performance of the employees by embracing a strong organizational culture (Shahzad et al. 2013). Therefore, in order to improve effectiveness, organizations must improve on their managerial aspect such as developing a suitable organizational culture and enhance efficiency by further flattering the organizational structure (Weiet al. 2011).

\subsection{Recommendations}

Based on the findings of this study, the researchers recommending that, ministry to should adopt a performance management system so as to achieve a high performance staff, rather than the traditional methods of performance evaluation. This is because PMS will help the ministry to address performance deficiencies and provide appropriate and specific feedback that will help in employee's career development. It will also provide a more dynamic system that will express the actual level of individual employee performance that will correspond with the nature of the jobs in the ministry.

\section{Conclusion}

This study was conducted in the Iran Ministry of Education which is a public service sector. Thus the result of the study is significant and applicable to the public sector or other organizations that have comparable 
characteristics. Additionally, this study represents one of the first steps toward understanding the relationship between HPWS, organizational culture and employee's performance in the context of public sector in Iran. Therefore, this unparalleled research highlights the significance of HPWS and organizational culture toward improving employees' performance. The research provides evidence that certain HPWS dimensions are associated with employee's performance. It is imperative to note that today organizations must excel to meet stakeholder's expectations; hence, the level of organizations awareness on HPWS and the ability to promote a better culture is vital to the survival of the organization.

\section{References}

Aksoy, M., Apak, S., Eren, E., \& Korkmaz, M. (2014). Analysis of the effect of organizational learning-based organizational culture on performance, job satisfaction and efficiency: A field study in banking sector. International Journal of Academic Research, 6(1), 301-313. https://doi.org/10.7813/2075-4124.2014/6-1/B.41

Alavi, M., Kayworth, T. R., \& Leidner, D. E. (2006).An empirical examination of the influence of organizational culture on knowledge management practices. Journal of management information systems, 22(3), 191-224. https://doi.org/10.2753/MIS0742-1222220307

Alegre, J., Sengupta, K., \& Lapiedra, R. (2013).Knowledge management and innovation performance in a high-tech SMEs industry. International Small Business Journal, 31(4), 454-470. https://doi.org/10.1177/0266242611417472

Anitha, J. (2014). Determinants of employee engagement and their impact on employee performance.International Journal of Productivity and Performance Management, 63(3), 308-323. https://doi.org/10.1108/IJPPM-01-2013-0008

Atteya, N. M. (2012). Testing the Impact of the Human Resource Management Practices on Job Performance: An Empirical Study in the Egyptian Joint Venture Petroleum Companies. International Journal of Business and Social Science, 3(9), 105-119.

Bhatti, M. A., \& Kaur, S. (2009). Factors effecting transfer of training: a fresh review. In 12th International Business Information Management Conference (IBIMA), Kuala Lumpur.

Boselie, P., Brewster, C., \& Paauwe, J. (2009). In search of balance managing the dualities of HRM: an overview of the issues. Personnel Review, 38(5), 461-471. https://doi.org/10.1108/00483480910977992

Danford, A., Richardson, M., Stewart, P., Tailby, S., \& Upchurch, M. (2008).Partnership, high performance work systems and quality of working life. New Technology, Work and Employment, 23(3), 151-166. https://doi.org/10.1111/j.1468-005X.2008.00210.x

De Waal, A. A. (2007). The characteristics of a high performance organization. Business Strategy Series, 8(3), 179-185. https://doi.org/10.1108/17515630710684178

Edwards, P., Ram, M., Sen Gupta, S., \& Tsai, C.J. (2006). The Structuring of Working Relationships in Small Firms: Towards a Formal Framework', Organization, 13(5), 701-724. https://doi.org/10.1177/1350508406067010

Ezati, M. (2017). Investigating the Factors Affecting the Performance of Teaching Academic Departments: Qualitative Study. Quarterly Journal of Research and Planning in Higher Education, 1391(65), 45-23.

Ferreira, P., Neira, I., \& Vieira, E. (2012). The strategic approach to the high- performance paradigm: a European perspective. Procedia-Social and Behavioural Sciences, 58, 474-482. https://doi.org/10.1016/j.sbspro.2012.09.1024

Goldston, B. K. (2007). The relationship between traits of organizational culture and job satisfaction within the healthcare setting. ProQuest.

Guthrie, J. P. (2001). High involvement work practices, turnover and productivity: evidence from New Zealand. Academy of Management Journal, 44(1), 180-190.

Hair, J. F., Tatham, R. L., Anderson, R. E., \& Black, W. (2010).Multivariate data analysis. Upper Saddle River, NJ: Pearson Prentice Hall.

Henri, J. (2006). Organizational culture and performance measurement systems. Journal of organizational science, 31(1), 77-103. https://doi.org/10.1016/j.aos.2004.10.003

Hilal, A. H. (2012). Teacher performance evaluation in Oman as perceived by evaluators. International 
Interdisciplinary Journal of Education, 1(10).

Huselid, M. A. (2017). The impact of human resource management practices on turnover, productivity, and corporate financial performance. Academy of Management Journal, 38(3), 635-672.

Jensen, J. M., Patel, P. C., \&Messersmith, J. G. (2013).HighPerformance Work Systems and Job Control Consequences for Anxiety, Role Overload, and Turnover Intentions. Journal of Management, 39(6), 1699-1724. https://doi.org/10.1177/0149206311419663

Lepak, D. P., Taylor, M. S., Tekleab, A., Marrone, J., \& Cohen, D. J. (2007). An examination of the use of high-investment human resource systems for core and support employees. Human Resource Management, 46(2), 223-246. https://doi.org/10.1002/hrm.20158

Messersmith, J. G., \& Guthrie, J. P. (2010). High performance work systems in emergent organizations: Implications for firm performance. Human resource management, 49(2), 241-264. https://doi.org/10.1002/hrm.20342

Moideenkutty, U., AlLamki, A., \& Murthy, Y. S. R. (2011). HRM practices and organizational performance in Oman. Personnel Review, 40(2), 239-251. https://doi.org/10.1108/00483481111106101

Mollick, E. (2012). People and process, suits and innovators: The role of individuals in firm performance. Strategic Management Journal, 33(9), 1001-1015. https://doi.org/10.1002/smj.1958

Moynihan, D. P. (2008). The dynamics of performance management: Constructing information and reform. Georgetown University Press.

Neil, J. (2009). Exploring research: New Jersey: Pearson Education International, Inc.

Ogbonna, E., \& Harris, L. (2000). Leadership Style, Organizational Culture and Performance: Empirical Evidence from UK Companies. International Journal of Human Resources Management, 11(4), 766-788. https://doi.org/10.1080/09585190050075114

Ovidiu Iliuta, D. (2014). The link between organizational culture and performance management practices: A case of it companies from Romania. The Annals of the University of Ooradea, 1156-1123.

Richard, P. J., Devinney, T. M., Yip, G. S., \& Johnson, G. (2009). Measuring organizational performance: Towards methodological best practice. Journal of management, 35(3), 718-804. https://doi.org/10.1177/0149206308330560

Scott, T., Mannion, R., Davies, H., \& Marshall, M. (2003). The quantitative measurement of organizational culture in health care: a review of the available instruments. Health services research, 38(3), 923-945. https://doi.org/10.1111/1475-6773.00154

Shahzad, F., Iqbal, Z., \&Gulzar, M. (2013). Impact of Organizational Culture on Employees Job Performance: An Empirical Study of Software Houses in Pakistan. Journal of Business Studies Quarterly, 5(2), 56-64.

Sparrowe, R. T., Liden, R. C., Wayne, S. J., \&Kraimer, M. L. (2001).Social networks and the performance of individuals and groups.Academy of Management Journal, 44(2), 316-325.

Takeuchi, N., Takeuchi, T., \& Toshima, Y. (2007). Fitting with organizations or jobs? A multilevel investigation of HR effects on employee behaviours. Discussion paper series No.2 JA-ASDP2007-2E, The Japanese Association of Administrative Science.

Tsui, P. L., Lin, Y. S., \& Yu, T. H. (2013). The influence of psychological contract and organizational commitment on hospitality employee performance. Social Behaviour and Personality: an international journal, 4l(3), 443-452. https://doi.org/10.2224/sbp.2013.41.3.443

Van den Berg, P. T., \&Wilderom, C. P. (2004). Defining, measuring, and comparing organisational cultures. Applied Psychology, 53(4), 570-582. https://doi.org/10.1111/j.1464-0597.2004.00189.x

Vlachos, I. P. (2009).The effects of human resource practices on firm growth.Human Resource Management: Issues, Challenges and Opportunities, 4(2), 17-34.

Wei, L. Q., Liu, J., \& Herndon, N. C. (2011). SHRM and product innovation: Testing the moderating effects of organizational culture and structure in Chinese firms. The International Journal of Human Resource Management, 22(1), 19-33. https://doi.org/10.1080/09585192.2011.538965

Wilderom, C. P., van den Berg, P. T., \&Wiersma, U. J. (2012). A longitudinal study of the effects of charismatic leadership and organizational culture on objective and perceived corporate performance. The Leadership Quarterly, 23(5), 835-848. https://doi.org/10.1016/j.leaqua.2012.04.002 
Wright, P. M., \& Nishii, L. H. (2012). Strategic human resource management and organizational behaviour: Exploring variance as an integrating framework. International Journal of Paauwe, 4(2), 97-110.

Zhang, M., Di Fan, D., \& Zhu, C. J. (2014). High-Performance Work Systems, Corporate Social Performance and Employee Outcomes: Exploring the Missing Links. Journal of Business Ethics, 120(3), 423-435. https://doi.org/10.1007/s10551-013-1672-8

Zikmund, W. G., Babin, B., Carr, J., \& Griffin, M. (2003).Business research methods (7th Ed). Cengage Learning.

\section{Copyrights}

Copyright for this article is retained by the author(s), with first publication rights granted to the journal.

This is an open-access article distributed under the terms and conditions of the Creative Commons Attribution license (http://creativecommons.org/licenses/by/4.0/). 